\title{
A Double Fluorescence Chimeric Limb Regeneration Model Reveals Muscle Fiber Reconnection During Axolotl Limb Regeneration
}

\author{
Modelo de Regeneración Quimérica de Doble Fluorescencia del Miembro Revela la \\ Reconexión de La Fibra Muscular Durante La Regeneración del Miembro Axolotl
}

\author{
Mu-Hui Wang1; Ting-Yu Huang²; Cheng-Han Wu' ${ }^{1}$; Ling-Ling Chiou² \& Hsuan-Shu Lee1,3,4
}

WANG, M. H.; HUANG, T. Y.; WU, C. H.; CHIOU, L. L. \& LEE, H. S. Double fluorescence chimeric limb regeneration model reveals muscle fiber reconnection during axolotl limb regeneration. Int. J. Morphol., 38(5):1485-1495, 2020.

SUMMARY: Axolotl limb regeneration is a fascinating characteristic that has attracted attention for several decades. Our previous studies on axolotl limb regeneration indicated that the satellite cells in the remnant muscles move distally into the blastema to regenerate new muscles that are separated by a gap from remnant muscles. Thereafter, the regenerative muscle fibers start to reconnect with remnant ones. In this study, the reconnection at the individual muscle fiber level was elucidated to test the hypothesis that this reconnection happens synchronously among involved muscles. Three pairs of EGFP ${ }^{+}$mid-bud stage blastemas were transplanted onto freshly amputated stumps of $\mathrm{RFP}^{+}$axolotls at the same thigh position to generate double fluorescence chimeric regenerative hindlimbs. These regenerative limbs were harvested very late far beyond they had reached the late differentiation stage. Fluorescence imaging of these limbs in cross sections revealed that in the proximal remnant part of the muscle fiber, reconnection occurred at a different pace among the muscles. In the major thigh muscle gracilis, the reconnection started from the periphery before it was completed. Furthermore, $\mathrm{RFP}^{+}$muscle fibers contributed to muscle regeneration in the distal regenerative parts. Intriguingly, this red cell contribution was limited to ventral superficial muscles of the calf. This kind of double fluorescence chimeric limb regeneration model may help increase the understanding of the patterning of axolotl limb regeneration in late stages.

KEY WORDS: Transgenic; EGFP; RFP; Blastema transplantation; Muscle fusion.

\section{INTRODUCTION}

Salamander limb regeneration has been a well-known biological miracle for over 200 years (Dinsmore, 1996). This fascinating biological issue has attracted many scientists to study the mechanisms in an attempt to elucidate why salamander limbs are able to regenerate, while human limbs cannot (Tanaka, 2003).

The contributions of muscle cells to regeneration in the regenerates have been beautifully revealed using lineage tracing techniques, which label mature muscle cells in salamanders (Sandoval-Guzmán et al., 2014). Surprisingly, it was found that there are fundamental differences in limb regeneration between newts and axolotls. In newts, satellite cells derived from dedifferentiated mature muscles contribute to the regenerates. However, in axolotls, the mature muscles do not contribute, albeit the regeneration is still successful. In further studies labeling resident satellite cells, it was finally shown that it is the resident satellite cells in the remnant muscles that contribute to the regenerates (Fei et al., 2017).

Accordingly, in axolotls, we also showed that satellite cells move out from the remnant muscles, which stay at the original location (Wu et al., 2015). The Pax7+ satellite cells migrate into the blastema and begin to proliferate. During the process of limb regeneration, these satellite cells gradually differentiate into immature muscle fibers in the regenerating region, while they are still separated with remnant muscles even in the late differentiation (LD) stage. In a serial horizontal section of a regenerative limb beyond the LD stage, a gap was persistently found between parental and regenerating muscles. The remnant muscle ends are

\footnotetext{
${ }^{1}$ Institute of Biotechnology, National Taiwan University, Taipei, Taiwan.

${ }^{2}$ Liver Disease Prevention and Treatment Research Foundation, Taipei, Taiwan.

${ }^{3}$ Department of Internal Medicine, National Taiwan University Hospital and National Taiwan University College of Medicine, Taipei, Taiwan.

${ }^{4}$ Agricultural Biotechnology Research Center, Academia Sinica, Taipei, Taiwan.

Funding: This study was supported by a grant to HSL from the Ministry of Science and Technology (MOST 106-2314-B-002 -017 -MY3), Taiwan.
} 
dedifferentiated in the bud stages and even in the LD stage. At some point after commencement of the LD stage, the remnant muscle ends are reconnected with the partially differentiated regenerating muscles. The undifferentiated status of both ends of the remnant and regenerating muscles may facilitate the reconnection probably because their sarcomere structures are still not well organized. Furthermore, by using a diffusion tensor tractography technique through magnetic resonance imaging (MRI), we not only confirmed the existence of a gap between parental and regenerating muscles at 9 weeks but also showed that reconnection took place starting 10 weeks postamputation in adult axolotls (Wu et al., 2017).

Our previous studies could not clearly show the events occurring in individual muscles. It is of interest to determine if this reconnection happens synchronously among the involved muscles.

In the present study, in 3 pairs of juvenile axolotls, we transplanted blastemas from EGFP-transgenic axolotls onto the fresh amputation ends at a specific thigh region of RFP-transgenic axolotls; this was done at the same proximaldistal level and at the same axes to examine the regenerating muscles. As a result, a red muscle fiber indicated that it originated from the remnant part, whereas a green muscle fiber originated from the transplanted blastemas. A combination of both red and green indicated that reconnection occurred between the red remnant and green blastema-derived muscle fibers. This strategy may lead to a more detailed understanding of muscle fiber reconnection in individual muscles.

\section{MATERIAL AND METHOD}

Plasmid construction. An EGFP-expression plasmid, pCXEGFP (Niwa et al., 1991; Okabe et al., 1997), was kindly gifted by Masaru Okabe and Jun-Ichi Miyazaki (Osaka University, Japan). We inserted an I-SceI recognition sequence flanked by a HindIII sequence (5'AAGCTTTAGGGATAACAGGGTAATAAGCTT-3') at the single HindIII restriction site (2996 bp) of pCX-EGFP to form the pCX-EGFP-SceI plasmid. To generate the pCXRFP-SceI plasmid, the EGFP sequence flanked by EcoRI sites in pCX-EGFP-SceI was substituted by a Texas Red sequence. The plasmids were purified using a Geneaid ${ }^{\mathrm{TM}}$ Midi Plasmid Kit (Geneaid, Taiwan).

Husbandry of axolotls and ethics statement. Adult or juvenile axolotls (Ambystoma mexicanum) were kept separately in individual fish tanks in an aquaria system as previously described (Wu et al., 2017; Huang et al., 2017). Animal care and experiments were approved by the Institutional Animal Care and Use Committee of National Taiwan University College of Medicine (Permit number: 20160535) and were conducted in accordance with the approved guidelines. All surgical procedures were under anesthesia in a $0.1 \%$ solution of ethyl 3-aminobenzoate methanesulfonate salt (MS-222, Sigma-Aldrich, St. Louis, MO, USA).

In vitro fertilization (IVF) and subsequent generation of transgenic axolotls. To control the timing of fertilization for plasmid injection, IVF was chosen instead of natural mating. The protocols for IVF and the genesis of transgenic axolotls were modified from previously reported methods (Mansour et al., 2011; Casco-Robles et al., 2011; Khattak et al., 2014). Before gamete collection, female axolotls were anaesthetized in a $0.1 \% \mathrm{MS}-222$ solution for $20 \mathrm{~min}$, followed by an intraperitoneal injection of 600 IU human chorionic gonadotrophin (hCG, Pregnyl®, N. V. Organon, Oss, The Netherlands). Females started to spawn 24-30 h after hCG injection, and then both male and female axolotls were anaesthetized. The semen was squeezed out and collected into a glass dish on ice. The eggs were mixed gently with semen and kept at room temperature for $5 \mathrm{~min}$ before the addition of saline fertilization buffer $(20 \mathrm{mM}$ $\mathrm{NaCl}, 1 \mathrm{mM} \mathrm{KCl}, 1 \mathrm{mM} \mathrm{Mg} \mathrm{SO}_{4}, 1 \mathrm{mM} \mathrm{CaCl}_{2}, 3 \mathrm{mM}$ $\mathrm{NaHCO}_{3}$, and $10 \mathrm{mM}$ Tris, pH 10). After 30-40 min of fertilization, the eggs were washed with $75 \%$ alcohol followed by sterile water. The eggs were then dejellied manually with fine tweezers and kept in $1 \times$ Marc's modified Ringer's solution (MMR; $1 \mathrm{M} \mathrm{NaCl}, 20 \mathrm{mM} \mathrm{KCl,} 10 \mathrm{mM}$ $\mathrm{MgSO}_{4}, 20 \mathrm{mM} \mathrm{CaCl}_{2}$, and $50 \mathrm{mM}$ HEPES, pH 7.4) with penicillin-streptomycin (pen-strep, Invitrogen, Carlsbad, CA, USA) on ice.

The fertilized and dejellied eggs were kept at $4{ }^{\circ} \mathrm{C}$ for maintenance at the one-cell stage until the microinjection of plasmids. Prior to injection, eggs of good quality were selected and aligned in plates containing $20 \%$ Ficoll $/ 1 \times$ $\mathrm{MMR} /$ pen-strep. Microinjection was performed using a pressure injector (Nanoinjector II, Drummond Scientific Company, Broomall, PA, USA) mounted alongside an Olympus Stereo SZX12 dissecting microscope. Glass capillary needles were prepared on a Flaming/Brown micropipette puller (Model P-97, Sutter Instruments, Novato, CA, USA). Needles were filled with either pCXEGFP-SceI or pCX-RFP-SceI plasmid ( $2 \mathrm{mg} / \mathrm{mL})$ plus ISceI enzyme $(1 \mathrm{U} / \mathrm{mL})$ in $1 \times$ cutsmart buffer (New England Biolabs, Ipswich, MA, USA). The injection volume for individual eggs was set at $2.3 \mathrm{~nL}$. After injection, the eggs were kept in $20 \%$ Ficoll/1× MMR solution for $2-3 \mathrm{~h}$ to prevent yolk leakage and then incubated in $5 \%$ Ficoll/ $/ 0.1 \times$ 
$\mathrm{MMR} /$ pen-strep overnight. Finally, they were transferred to $0.1 \times \mathrm{MMR} /$ pen-strep until the hatching stage, at which point the animals were kept in aerated tap water at room temperature. All the solutions used for microinjection and embryo rearing were sterilized with $0.22 \mathrm{~mm}$ filters. The founder (F0) transgenic animals were used to generate F1 axolotls by IVF (Fig. 1A).

Blastema transplantation. Transplantation of green blastemas onto red recipients was performed with 3 pairs of juvenile transgenic axolotls, namely, $9 \mathrm{~cm}$ leutic to leutic $\mathrm{F} 0,4 \mathrm{~cm}$ leutic to wild type $\mathrm{F} 1$, and $7 \mathrm{~cm}$ leutic to leutic $\mathrm{F} 1$, to yield the recipient axolotls F0, F1-1, and F1-2, respectively. The body length was measured from the snout to the tail end. The EGFP-transgenic (EGFP-Tg) axolotls were amputated at the lower third of their right thigh. When the regeneration reached mid-bud stage after 10 days in F0 donors and 8 days in F1-1 and F1-2 donor axolotls, another pair of RFP-transgenic (RFP-Tg) juvenile axolotls were
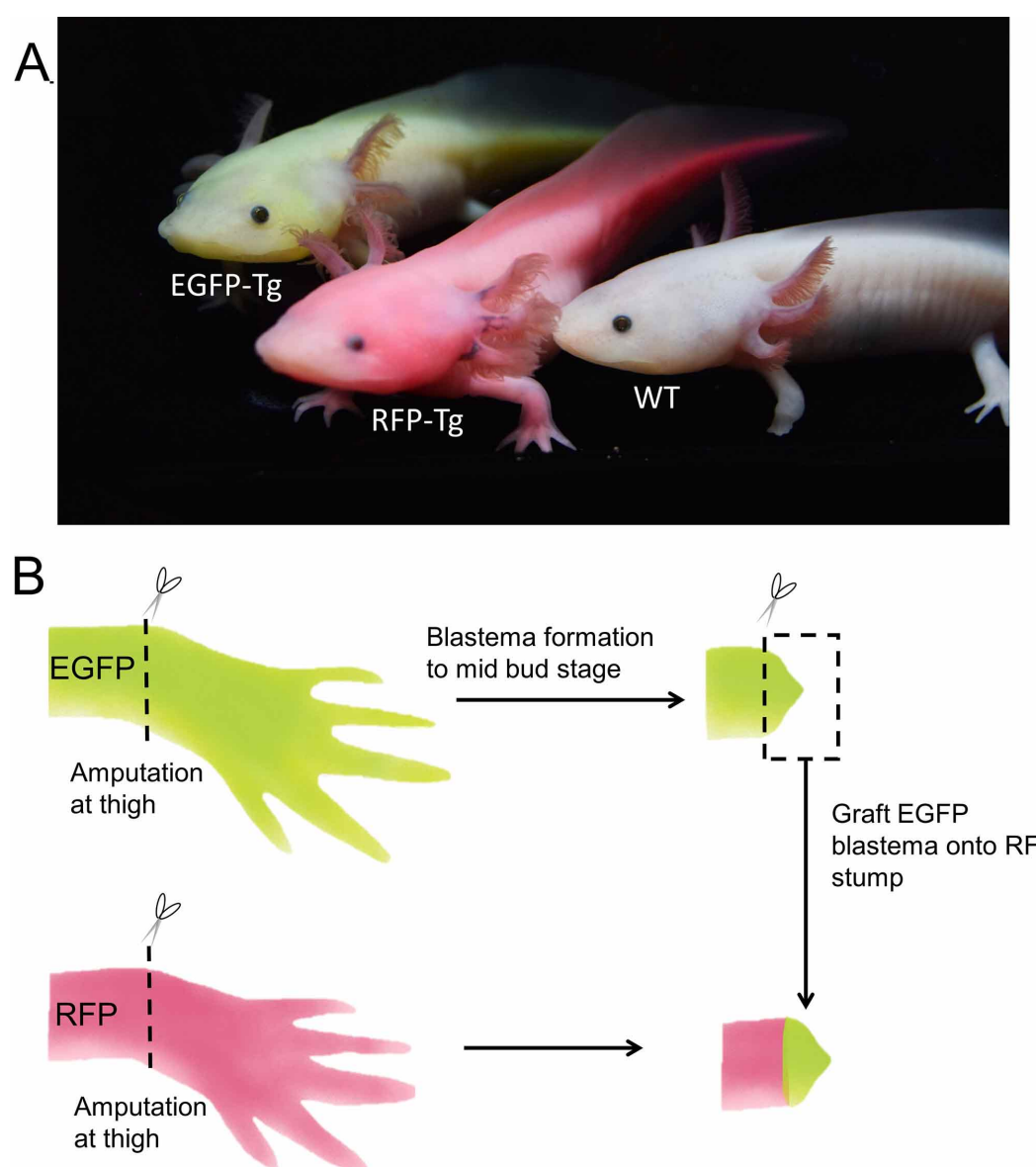

Fig. 1. Generation of fluorescence transgenic axolotls and schema of blastema transplantation. (A) The EGFP- and RFP-transgenic axolotls could be easily recognized under daylight conditions. (B) Schema of transplanting green mid-bud stage blastema onto the corresponding red stump. EGFP-Tg= EGFP-transgenic; RFP-Tg= RFP-transgenic; WT= wild type. amputated at the lower third of their right thighs. Then, the blastemas of the EGFP-Tg axolotls were resected and transplanted carefully onto the freshly cut surface of the RFP-Tg axolotls' right thighs at the same anterior-posterior and dorsal-ventral axes. Blood coming out of the freshly amputated site served as an adhesive to attach the transplanted blastemas. The recipient animals were covered with a moist Kimwipe and left on ice for $1 \mathrm{~h}$ to allow the blastemas to stick firmly to the recipients' stump before they were put back into the aquatic environment (Fig. 1B).

Tissue processing and sectioning. The recipients' right hindlimbs were harvested 88 days posttransplantation (dpt) for the $\mathrm{F} 0$ recipient (reached $14 \mathrm{~cm}$ snout to tail tip length), $55 \mathrm{dpt}$ for the $\mathrm{F} 1-1$ recipient (reached $7 \mathrm{~cm}$ ), and $100 \mathrm{dpt}$ for the F1-2 recipient (reached $12 \mathrm{~cm}$, Fig. 2). The right hindlimbs of the RFP-Tg recipient axolotls were cut from the upper thigh and fixed in $3.7 \%$ paraformaldehyde overnight at $4{ }^{\circ} \mathrm{C}$. Then, these hindlimbs were vertically embedded in Cryomatrix (Thermo Scientific, Miami, FL, USA) and frozen at $-80{ }^{\circ} \mathrm{C}$ until they were used for sectioning. These blocks were serially sectioned at an $8-\mu \mathrm{m}$ thickness, and the sections were serially numbered from thigh ends. The sections were directly examined under a confocal microscope with staining of nuclei by Hoechst 34580 (Molecular Probes, Eugene, OR, USA).

Gross and histology imaging. Gross fluorescence images were obtained using an Olympus SZX7 microscope (Olympus, Tokyo, Japan) with the usage of an extra equipped light-emitting diode (LED) lightening device. Sections for examining the transgenic fluorescence were imaged on a ZEISS LSM 880 confocal microscope (Carl Zeiss Microscopy, Thornwood, NY, USA).

Differentiating muscle fibers according to their fluorescence expression. Using Adobe Photoshop CC (Adobe Inc., San Jose, CA, USA), the confocal microscopy photos of green and red fluorescence from the same area were displayed separately and merged in two layers. The fibers containing only green or red fluorescence were labeled green $(\mathrm{G})$-only and red (R)-only fibers, respectively, while fibers containing both green and red fluorescence were labeled red plus green $(\mathrm{R}+\mathrm{G})$ fibers (Fig. 3). The numbers of the three kinds of fibers were separately quantified on screen. 


\section{RESULTS}

Generation of EGFP- and RFP-Tg axolotls. The EGFP- and RFP-Tg F0 and F1 axolotls were reared to the juvenile stage before blastema transplantation. The transgenic colors could be easily recognized even under a daylight lamp (Fig. 1A).

Development of green regenerating missing parts on the red recipient axolotls' hindlimbs. Following blastema transplantation, the distal part of the lost hindlimbs accurately and gradually grew up with green color, as shown in Fig. 2. As expected, the speed of regeneration was inversely correlated with body length. The F0 axolotl reached the LD stage at $45 \mathrm{dpt}$; F1-1, at 17 $\mathrm{dpt}$; and F1-2, at $26 \mathrm{dpt}$, suggesting the regeneration speed was fastest in F1-1 and slowest in F0. The respective harvesting times and body lengths were $88 \mathrm{dpt}$ and $14 \mathrm{~cm}$ in F0 (Fig. 2A), $55 \mathrm{dpt}$ and $7 \mathrm{~cm}$ in F1-1 (Fig. 2B), and $100 \mathrm{dpt}$ and $12 \mathrm{~cm}$ in F1-2 (Fig. 2C). Interestingly, a narrow green fluorescence-containing dorsal muscle was noted extending from the green regenerate into as high as the pelvis in the F1-2 recipient axolotl at $88 \mathrm{dpt}$ (green arrowheads in Fig. 2C).

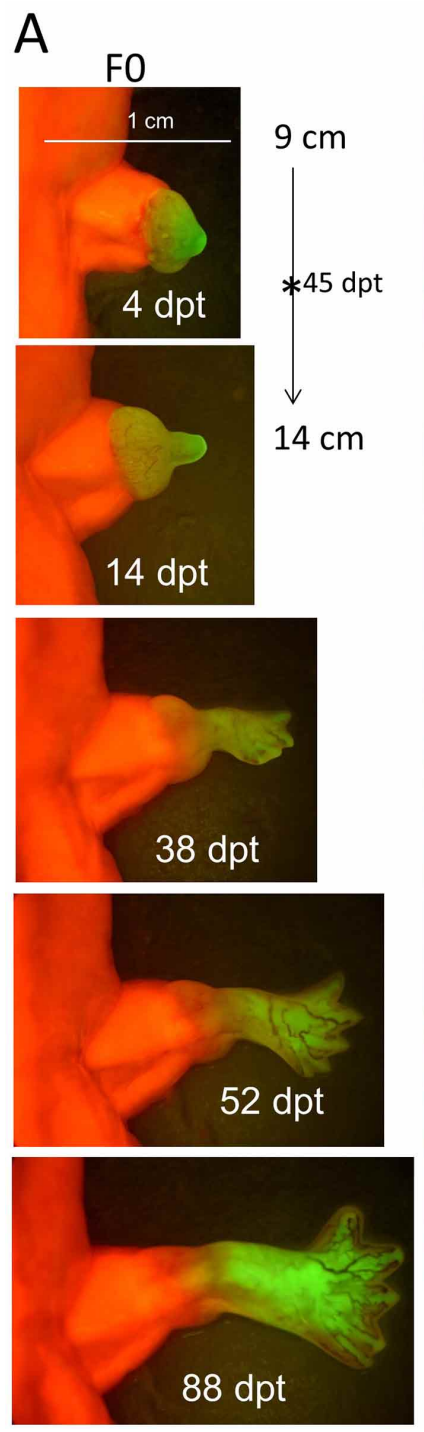

B
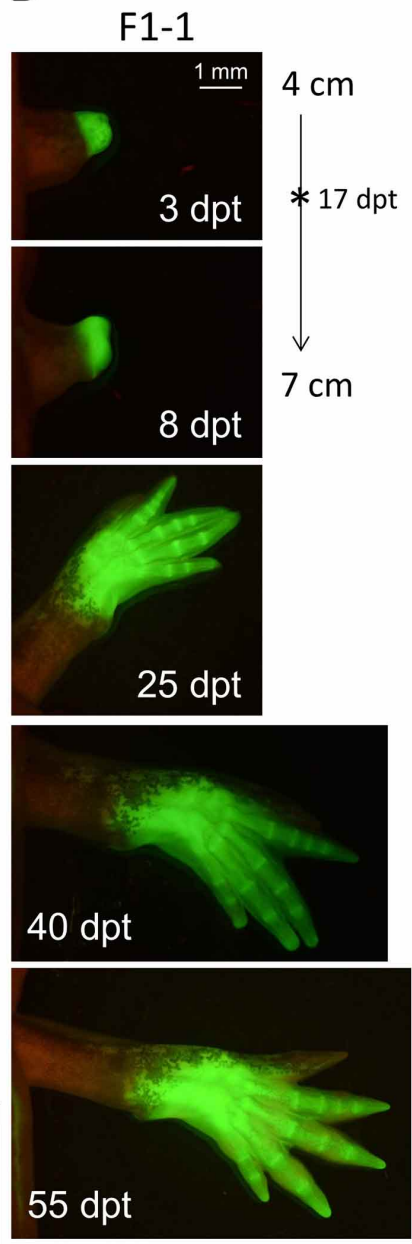

C
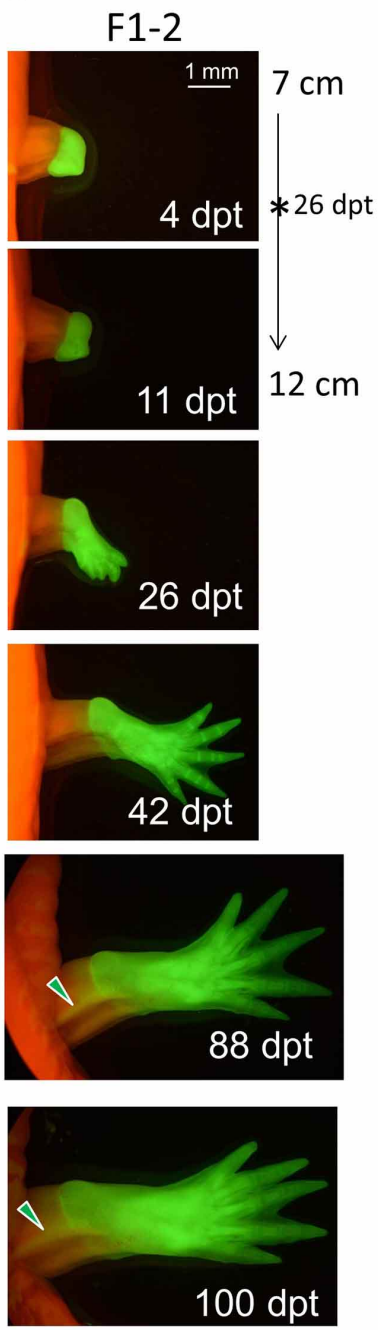

Fig. 2. Gradual regeneration and growth of the double fluorescence chimeric hindlimbs of the F0 (A), F1-1 (B), and F1-2 (C) axolotl in time series. dpt= days posttransplantation. The body length from the day of transplantation to the day of limb harvesting was indicated. Asterisks indicate the date that the axolotls reached the late differentiation stage. Scale bar in $A=1 \mathrm{~cm}$; in $B$ and $C=1 \mathrm{~mm}$. 
Fluorescence images of selective sections. Under confocal microscopy, muscle fibers were divided into Ronly, G-only, and R+G, as shown in Figure 3. R-only fibers are from the recipient parental part, G-only fibers must be derived from the transplanted green blastema, and the $R+G$ fibers indicate an event of fusion or connection between the progenitor cells or fibers from the two parts.

Figure 4 shows a series of images of representative sections of the F0 axolotl. Most fibers in the proximal parental parts (above the knee) were R-only (69\%-93\%, Fig. 4B-D and 4G). In contrast, a few fibers were R+G (0.7 $\%-30 \%)$, and only very few were G-only (0-5\%). Very strikingly, in this stage, most of the $\mathrm{EGFP}^{+}$fibers $(\mathrm{R}+\mathrm{G}$ plus G-only) were at the periphery of the major muscle gracilis (GRA, Fig. 4C-D). Interestingly, a small bundle of muscle fibers in the No. 75 section (insets indicated by an arrow in Fig. 4D) were G-only. In the below-knee sections (Fig. 4E, $\mathrm{F}$ ), the ventral muscles also contained $\mathrm{RFP}^{+}$fibers (mostly $\mathrm{R}+\mathrm{G}, 36 \%$, and a few R-only, $4 \%$ ). More intriguingly, as shown in Figure 4F, the No. 124 section of calf showed that the $\mathrm{RFP}^{+}$fibers were exclusively confined in the ventral superficial muscles ischioflexorius (ISF), flexor digitorum communis (FDC), and femorofibularis (FMFB) but not in deep muscles such as the interosseus cruris (IOC). The dorsal muscles, extensor cruris tibialis (ECT), extensor tarsi tibialis (ETT), extensor digitorum longus (EDL), and extensor cruris et tarsi fibularis (ECTF) did not contain $\mathrm{RFP}^{+}$ fibers. The nomenclature of muscles follows Ashley-Ross (1992) and Diogo et al. $(2014,2018)$.

Figure 5 shows select images at different thigh levels of F1-1 and F1-2. First, we focused on the narrow EGFP ${ }^{+}$ dorsal muscle of the F1-2 axolotl shown in Figure 2C and identified it as tenuissimus (T, Fig. 5A, at a very proximal level of No. 47). The enlarged photos (Fig. 5A1 and 5A2) show that all the $\mathrm{EGFP}^{+}$fibers were $\mathrm{R}+\mathrm{G}$ fibers. Interestingly, the size of the $\mathrm{R}+\mathrm{G}$ fibers (to the right of the dashed line) was larger than that of R-only fibers (to the left of the dashed line).
Then, we compared the cross sections of F1-1 (Fig. 5B, No. 57) and F1-2 (Fig. 5C, No. 107) at approximately similar levels of thigh. Both sections showed similar structures of pubotibialis (PTB) and GRA. Consistent with the F0 axolotl at that thigh level (Fig. 4D), EGFP ${ }^{+}$fibers in F1-1 (Figs. 5B, B1, and B2) were mostly confined to the outer periphery of GRA. The muscle fibers were mostly Ronly $(60 \%)$, and very few were G-only ( $2 \%)$; however, F1$2 \mathrm{EGFP}^{+}$fibers appeared evenly in GRA (Figs. 5C, C1, and $\mathrm{C} 2$ ). These findings suggested that the muscle fiber reconnection in GRA occurred from the outer periphery towards the inner side. The epidermis at this level was RFP ${ }^{+}$ in both animals.

Selected below-knee photos of F1-1 and F1-2 are shown in Figure 6. Consistent with the F0 axolotl, dorsal muscles ECT, ETT, EDL, and ETCF and the deep ventral muscle IOC in F1-1 and F1-2 were free of $\mathrm{RFP}^{+}$fibers (Fig. 6A, D), whereas superficial ventral muscles ISF, FDC, and FMFB in F1-1 contained RFP ${ }^{+}$fibers (Fig. 6A). Contribution of $\mathrm{RFP}^{+}$fibers to FDC in F1-1 went as far as the ankle (Fig. 6B) and the foot (Fig. 6C). Most fibers in FDC were $\mathrm{R}+\mathrm{G}$ ( $45 \%$ to $84 \%$ ) in these below-knee sections, but there were also R-only (6\% to $15 \%$ ) and G-only fibers ( $4 \%$ to $48 \%$ ). The section level in Figure 6D of F1-2 was higher than that of Figure 6A in F1-1 and showed that the ventral superficial muscles adductor femoris (ADD), PTB, GRA, FMFB, and ISF in Figure 6D had $\mathrm{RFP}^{+}$fibers. Strikingly, FDC in F1-2 did not have $\mathrm{RFP}^{+}$fibers (Fig. 6D, E).

Interestingly, many $\mathrm{RFP}^{+}$chondrocytes appeared at the proximal calf (Fig. 6A1), whereas there were only a few at the ankle level (Fig. 6B1), and none found at the foot level (Fig. 6C1). Strangely, approximately half the circumference of the epidermal cells in the proximal calf (Fig. 6A), ankle (Fig. 6B), and foot (Fig. 6C) were $\mathrm{RFP}^{+}$in $\mathrm{F} 1-1$. However, in F1-2, only a very small area was $\mathrm{RFP}^{+}$in the proximal calf (Fig. 6D), and none of the ankle was RFP ${ }^{+}$ (Fig. 6E).
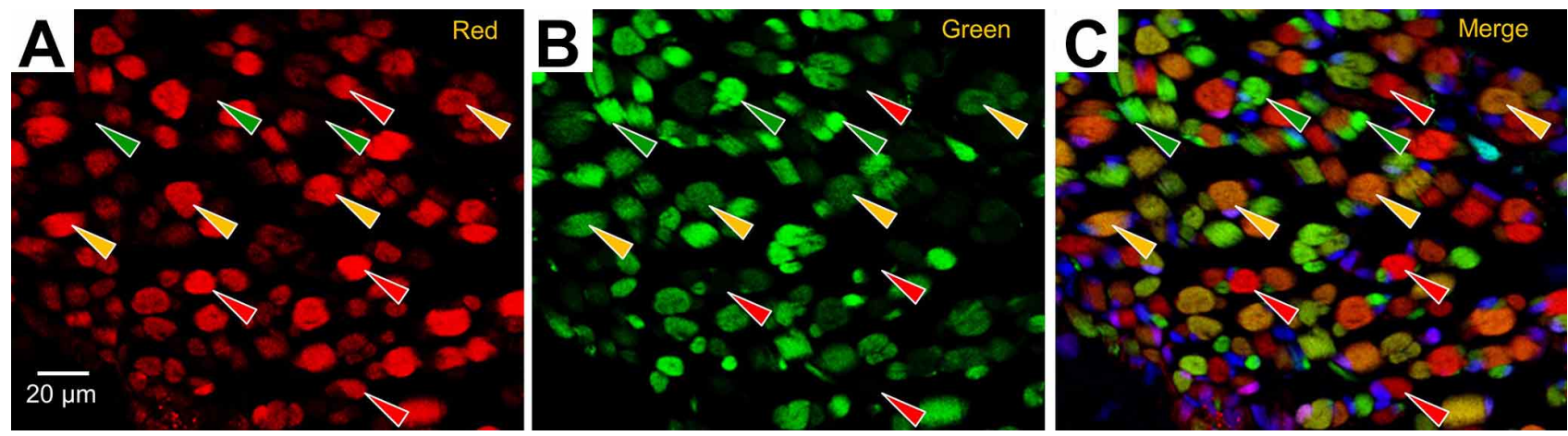

Fig. 3. Differentiating muscle fibers according to their fluorescence expression. The confocal microscopy images of green and red were separately displayed using Photoshop. Fibers containing only green or red fluorescence were labeled G-only (green arrowheads) or R-only (red arrowheads) fibers, respectively. The fibers containing both green and red fluorescence were labeled $\mathrm{R}+\mathrm{G}$ (yellow arrowheads) fibers. 

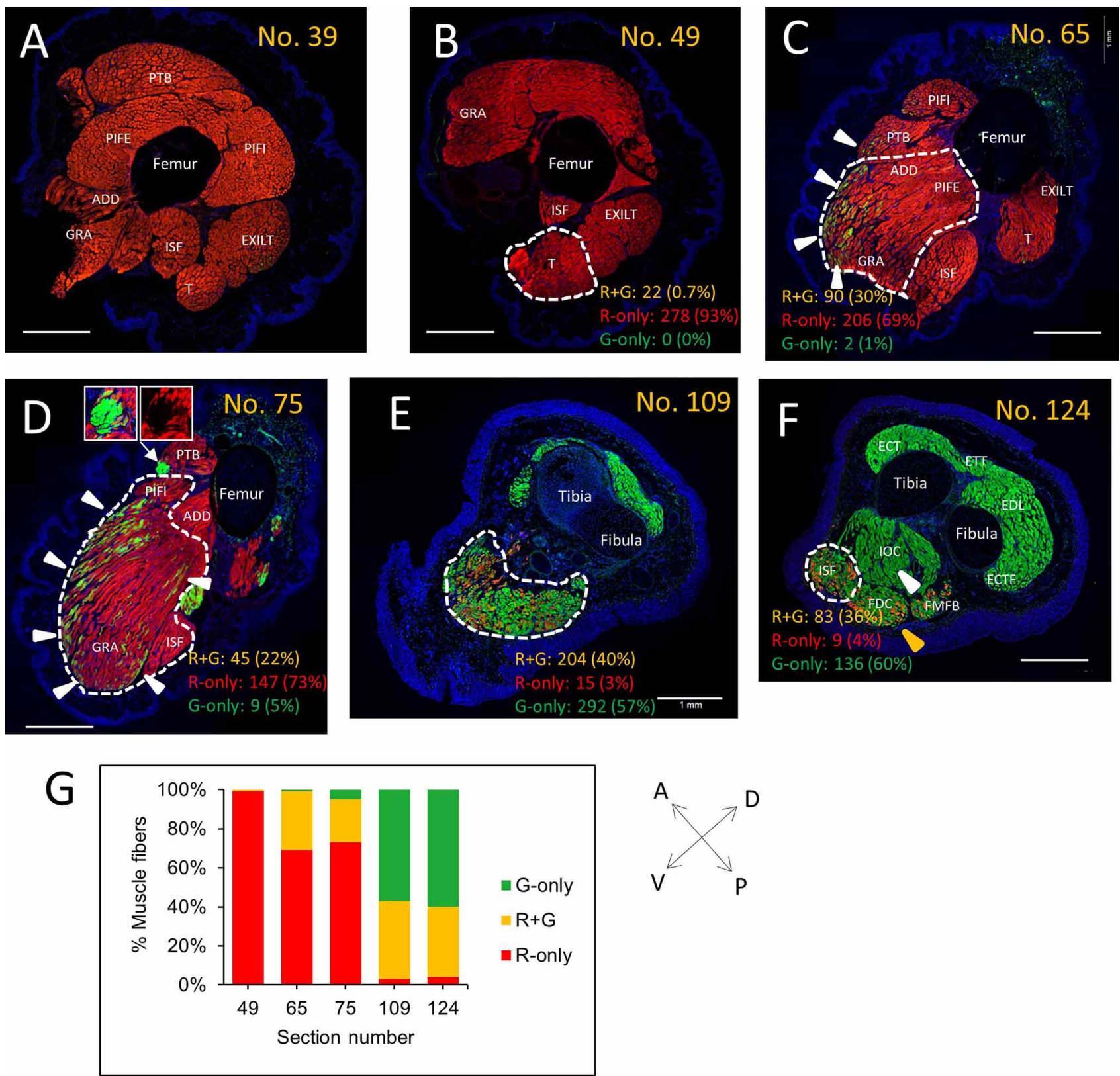

Fig. 4. Fluorescence histology of representative sections indicated by section numbers in the F0 axolotl. A to F show the selected images of the indicated section numbers. Axes are indicated by double arrows. $\mathrm{D}=$ dorsal; $\mathrm{V}=$ ventral; $\mathrm{A}=$ anterior; $\mathrm{P}=$ posterior. The femur, tibia, and fibula in each section are indicated. The dashed-line circles indicate the areas where the muscle fibers were counted for R-only, Gonly, and R+G. White arrowheads in $\mathrm{C}$ and $\mathrm{D}$ demarcate the green color muscle fibers (mostly $\mathrm{R}+\mathrm{G}$ and very few G-only), which are more frequently located at the periphery of the muscles. The white arrow in D marks an interesting area containing almost exclusively Gonly fibers. (G) Percentage of R-only, $\mathrm{R}+\mathrm{G}$, and G-only muscle fibers in the circled areas in representative sections are arranged in a bar chart. $\mathrm{PIFI}=$ Puboishiofemoralis internus; $\mathrm{PTB}=$ Pubotibialis; $\mathrm{PIFE}=$ Puboishiofemoralis externus; $\mathrm{EXILT}=\mathrm{Extensor}$ iliotibialis; $\mathrm{T}=$ Tenuissimus; ISF= Ischioflexorius; $\mathrm{ADD}=$ Adductor profundus; $\mathrm{FDC}=$ Flexor digitorum communis; FMFB= Femorofibularis; $\mathrm{ECT}=$ Extensor cruris tibialis; ETT $=$ Extensor tarsi tibialis; EDL= Extensor digitorum longus; ECTF $=$ Extensor cruris et tarsi fibularis; $\mathrm{IOC}=$ Interosseus cruris; GRA= Gracilis. 

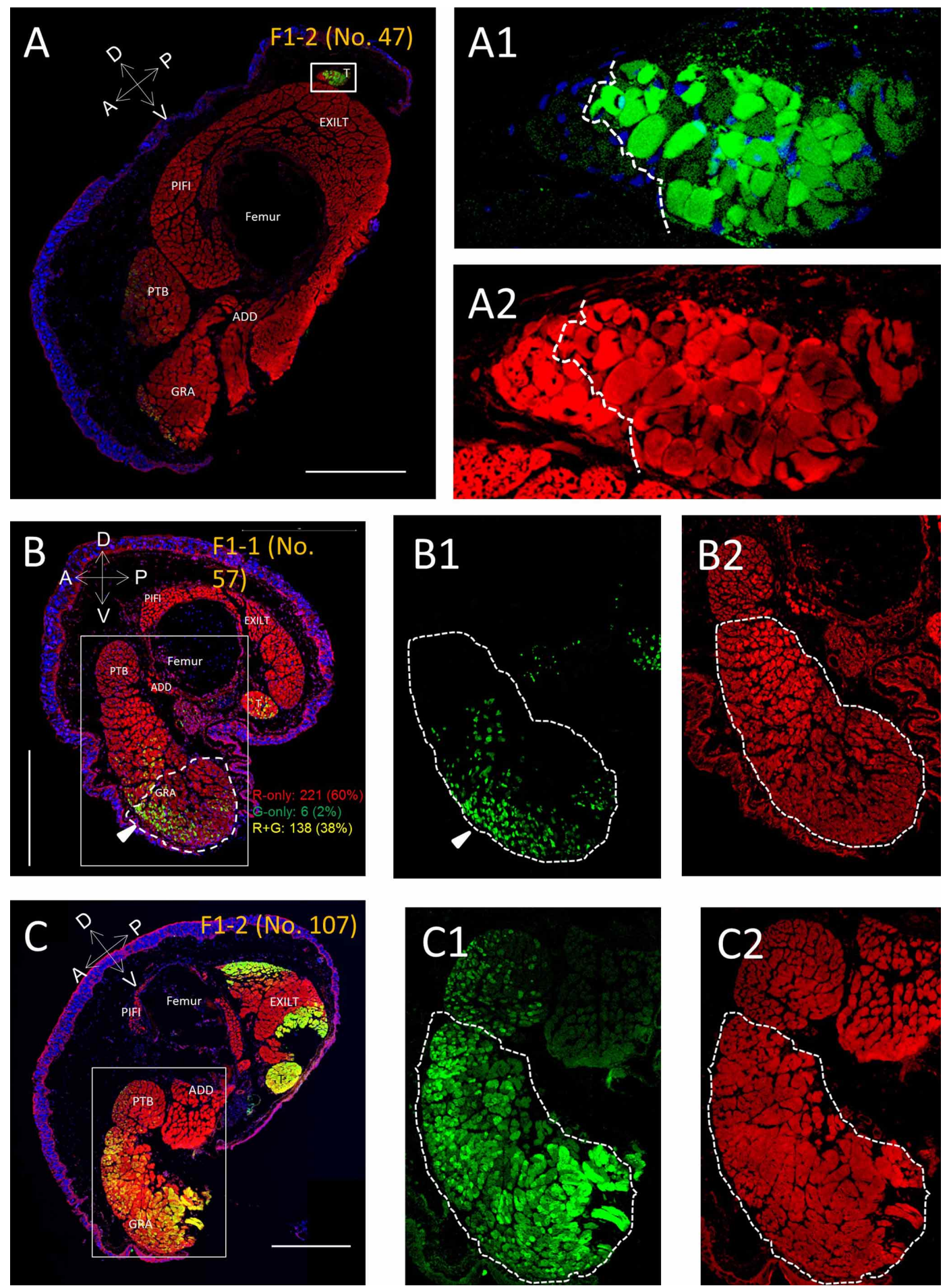

Fig. 5. Representative fluorescence images at the proximal thigh in F1-1 and F1-2 axolotls. (A) In F1-2, the EGFP muscle that extended to the very proximal dorsal region shown grossly in Fig. $2 \mathrm{C}$ was indicated to be the tenuissimus (T). Enlarged photos of the boxed area in A are presented in green (A1) and red (A2). A dashed-line separates the group of R-only fibers (to the left) and $\mathrm{R}+\mathrm{G}$ fibers (to the right). Images of an approximately similar thigh level in F1-1 (B) and F1-2 (C) are shown. Boxed areas including the gracilic muscle in B and C are displayed of green (B1 and $\mathrm{C} 1$ ) and red (B2 and $\mathrm{C} 2$ ), respectively. White arrowheads on B and B1 indicate the outer periphery location of green fluorescence-containing fibers. In contrast, the $\mathrm{EGFP}^{+}$fibers in this area of $\mathrm{C}$ are evenly distributed in $\mathrm{C}$. The muscle fibers in the circle line area in B are counted. Scale bars= $1 \mathrm{~mm}$. Axes are indicated by double arrows. 

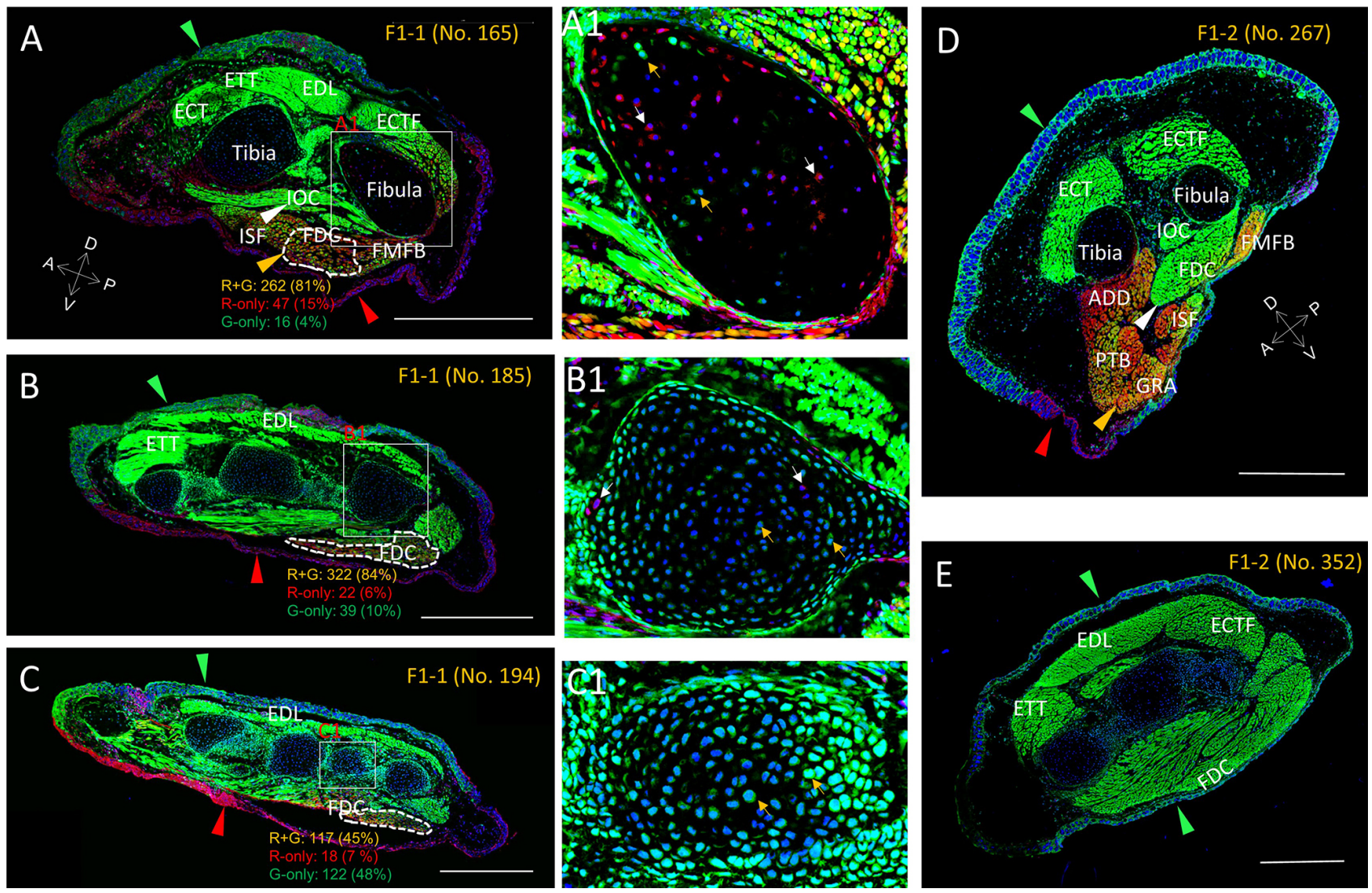

Fig. 6. Representative below-knee section images in F1-1 and F1-2. Upper calf (A), ankle (B), and foot (C) in F1-1, and upper calf (D) and ankle (E) in F1-2 are shown. Green arrowheads= EGFP-expressing skin; red arrowheads= RFP-expressing skin; white arrowheads= calf deep muscle without red fluorescence; yellow arrowheads= calf ventral muscles with red fluorescence. Boxed skeletal areas in A, B, and $\mathrm{C}$ are enlarged in $\mathrm{A} 1, \mathrm{~B} 1$, and $\mathrm{C} 1$, respectively. White arrows = red chondrocytes; yellow arrows= green chondrocytes. The muscle fibers in the circle line areas in A, B and C are counted. Scale bars= $1 \mathrm{~mm}$. Axes are indicated by double arrows.

\section{DISCUSSION}

Our previous studies by histology (Wu et al., 2015) and MRI (Wu et al., 2017) showed that during the LD stage of axolotl limb regeneration, the newly formed distal muscles are still separated from the parental muscles by a gap. It is not until later stages that the regenerated new muscle fibers grow and extend proximally to reconnect with the fibers in the parental muscles. Continuity between remnant and regenerative muscle fibers could be shown by MRI. However, this technique could only provide gross images of muscles and was not powerful enough to show the details of individual muscles. To overcome this, we developed a double fluorescence chimeric limb regeneration technique to examine the reconnection at the individual muscle fiber level.

Transplantation of $\mathrm{GFP}^{+}$blastemas to wild type axolotls has already been done to elucidate the proximodistal outcome of limb regeneration (Nacu et al., 2013;
Maden et al., 2015). However, we believe this approach cannot differentiate between a $\mathrm{GFP}^{+}$muscle that is purely derived from the transplanted blastema or a fusion between $\mathrm{GFP}^{+}$and wild type.

In keeping with our previous findings, the present chimeric limb regeneration technique also revealed several $\mathrm{R}+\mathrm{G}$ fibers in the proximal parental muscles (Figs. 4 and 5). The existence of these fibers strongly suggested that a reconnection between fibers from both sides had occurred before tissue harvesting. There were very few G-only fibers $(0$ to $5 \%)$ in these parental muscles. We hypothesized that these G-only fibers represented fibers extending up from the $\mathrm{EGFP}^{+}$regenerative part that had not yet met the right fibers to connect with in the corresponding remnant muscles. $\mathrm{GFP}^{+}$muscle fibers located proximal to the transplantation plane have also been identified in both of 
the previous GFP to wild type transplantation studies (Nacu et al.; Maden et al., 2015). Thus, muscle cells were believed to be against the law of distal transformation (Butler, 1955). $\mathrm{Nacu}$ et al. further demonstrated the existence of $\mathrm{PAX}^{+} \mathrm{GFP}^{+}$satellite cells in the proximal remnant muscles. These satellite cells must have been derived from the transplantedblastema and had become proximal. Thus, the authors seemed to favor that the $\mathrm{GFP}^{+}$muscle fibers in the proximal remnant muscles were generated from proximal blastema myogenic cells instead of a cell fusion between both. However, we propose another explanation for the appearance of $\mathrm{GFP}^{+}$muscles in the proximal muscles of their studies: the appearance occurs due to reconnection between remnant and regenerating muscle fibers. Logically, this possibility makes more biological sense for two reasons. First, it must be more difficult for the regenerative muscle fibers to grow upward to their far away sites of origin than for reconnection to occur. Second, the preexisting fibers are still present in the remnant muscles; therefore, if these newly formed $\mathrm{GFP}^{+}$muscle fibers did exist independently from the remnant muscle fibers, the number of muscle fibers within a muscle would double, which is not the case.

Figure 4D shows a small muscle bundle composed of almost exclusively G-only fibers. The reason for this is unknown. It is likely that the corresponding parental muscle part was destroyed or withdrew upward due to greater physical elastic properties than the other muscles.

The present results show that the reconnection was not synchronized. The pace was different among individual muscles. The T muscle was the fastest in F1-2 but not in the others.

Another important finding in the present study is that the reconnection seemed to start from the periphery of muscles, which was exemplified by GRA (Fig. 4C and $\mathrm{D}$ and Fig. 5B). Based on this, the regeneration stage at harvesting time in F0 (43 days postreaching LD stage) and F1-1 (38 days postreaching LD stage) seemed very close. F1-1 was smaller in size compared to the F0 axolotl (initially $4 \mathrm{~cm}$ vs. $9 \mathrm{~cm}$ ); thus, it regenerated faster. The regenerative stage of F1-2 at harvest time (74 days postreaching the LD stage) was much later than that of the other two. The GRA of F1-2 showed homogenous distribution of $\mathrm{EGFP}^{+}$fibers (Fig. 5C1). These findings strongly suggest that the reconnection started from the periphery (F0 and F1-1) before it was completed (F1-2). It is rational to achieve a perfect regeneration if muscle fiber reconnection commences at the periphery. This property may confine muscle mass and help individual interior fibers meet and reconnect with their corresponding parental fibers.
It is still unknown whether this reconnection occurs end-to-end, end-to-side or side-to-side between fibers from both parts or, alternatively, through fusion mediated by newly proximal green satellite cells ( $\mathrm{Nacu}$ et al.). Nevertheless, this reconnection might increase the thickness of the reconnected muscle fibers, as shown in Figure 5A2. There must be very fascinating molecular and cellular mechanisms coordinating individual regenerating muscle fibers to precisely find and connect to their corresponding parental fibers. Our current studies still did not show when the reconnection is completed.

Interestingly, $\mathrm{RFP}^{+}$fibers appeared in the calf muscles, which are definitely newly regenerative parts below the amputation plane (Figs. 4F, 6A, and 6D). There were even R-only fibers, though very few ( $2 \%$ to $4 \%$ in F0, Figs. 4E and F; $6 \%$ to $15 \%$ in F1-1, Figs. 6A-C). Our previous results (Wu et al., 2015) and those of SandovalGuzmán et al. and Fei et al. suggested that the satellite cells in the remnant muscles migrate distally to contribute to muscle regeneration after limb amputation in axolotls. It is therefore likely that the $\mathrm{RFP}^{+}$satellite cells in the remnant muscles of the freshly amputated thigh migrated distally across the transplantation interface into the regenerating part to contribute to muscle regeneration. These $\mathrm{RFP}^{+}$satellite cells then differentiated into muscle fibers in the regenerative parts. Most of the $\mathrm{RFP}^{+}$fibers here were $R+G$ (Figs. 4E, F), suggesting that either fusion between $\mathrm{RFP}^{+}$and $\mathrm{EGFP}^{+}$satellite cells or connection between differentiated $\mathrm{RFP}^{+}$and $\mathrm{EGFP}^{+}$fibers had happened during this period. The R-only fibers could be identified from the upper calf to the foot area (6\% to 15 $\%$, Figs. 6A, B, and C), suggesting that the R-only fibers could independently contribute to the regenerative parts.

More interestingly, $\mathrm{RFP}^{+}$fibers in the calf part were exclusively confined to the superficial ventral muscles ISF, FDC, PTB, and FMFB. As shown in Figure 6C, this contribution in FDC might be as far as the foot level. However, the dorsal muscles ECT, ETT, EDL, and ECTF and deep ventral muscle IOC were free of $\mathrm{RFP}^{+}$fibers. All these dorsal muscles originate from either femoral epicondyles or tibial condyles, whereas the ventral muscles ISF and PTB originate from the pelvic bone, and FMFB originates from middle femur. It is conceivable that these dorsal muscles are below the amputation plane and completely lost during amputation, whereas these superficial ventral muscles pass through the amputation plane; thus, they suffered from cutting during amputation procedures. The transplanted blastemas already contained early-coming $\mathrm{EGFP}^{+}$satellite cells; however, after amputation and transplantation, the remnant muscles might give rise to late-coming $\mathrm{RFP}^{+}$satellite cells, which migrate 
through the amputation plane into the regenerated part. There could be a sense of commitment in these satellite cells. In the ventral superficial muscles, the $\mathrm{RFP}^{+}$latecoming satellite cells might have self-commitment, which allows them to compete with or join the early-coming $\mathrm{EGFP}^{+}$satellite cells and to grow into the regenerative parts. However, in the dorsal side, the $\mathrm{EGFP}^{+}$early-coming satellite cells might dominate the regeneration; thus, the late-coming $\mathrm{RFP}^{+}$satellite cells fail to contribute. One question is where have the dorsal late-coming $\mathrm{RFP}^{+}$ satellite cells gone? It is an interesting issue that remains unknown.

Regarding cartilage regeneration, $\mathrm{RFP}^{+}$ chondrocytes might contribute to the regenerative parts in the proximal calf but not in the distal part. This would indicate that the patterning of distal cartilage had already committed in the $\mathrm{EGFP}^{+}$mid bud-stage blastema.

Strangely, the $\mathrm{RFP}^{+}$and $\mathrm{EGFP}^{+}$epidermis was shown as half-and-half in the regenerative parts of F1-1 (Figs. 6A, B, and C). However, most of the epidermis in the regenerative parts of $\mathrm{F} 1-2$ was $\mathrm{EGFP}^{+}$. These data conflict with the results in a previous report (Maden et al., 2015). In their experiments of transplanting $\mathrm{GFP}^{+}$ blastema onto wild-type axolotls, the authors found that in most of their animals, the epidermis of the grafted $\mathrm{GFP}^{+}$ blastema was completely replaced by host epidermis. The reason for this discrepancy is unknown. It could be a technical issue during the transplantation experiment on the small animals. We could have included a tiny part of $\mathrm{EGFP}^{+}$stump tissue with the blastema for transplantation, and this stump tissue could prevent replacement by the host $\mathrm{RFP}^{+}$epidermis.

Using blastema transplantation between different color transgenic axolotls, many interesting new findings of muscle regeneration in the very late stage of limb regeneration were discovered as described above. However, more unknown phenomena remain and deserve further investigation.

\section{ACKNOWLEDGMENTS}

We thank the Microscopy Core Facility of Department of Medical Research at National Taiwan University Hospital for the technical support. This study was supported by a grant to HSL from Ministry of Science and Technology (MOST 106-2314-B-002 -017 -MY3), Taiwan.
WANG, M. H.; HUANG, T. Y.; WU, C. H.; CHIOU, L. L. \& LEE, H. S. Modelo de regeneración quimérica de doble fluorescencia del miembro revela la reconexión de la fibra muscular durante la regeneración del miembro axolotl. Int. J. Morphol., 38(5):1485-1495, 2020.

RESUMEN: La regeneración del miembro de Axolotl es una característica fascinante que ha llamado la atención durante varias décadas. Nuestros estudios previos sobre la regeneración del miembro del Axolotl indicaron que las células satélite en los músculos remanentes se mueven distalmente hacia el blastema para regenerar nuevos músculos que están separados por una brecha de músculos remanentes. A partir de entonces, las fibras musculares regenerativas comienzan a reconectarse con las restantes. En este estudio, se aclaró la reconexión a nivel de fibra muscular individual para probar la hipótesis de que esta reconexión ocurre sincrónicamente entre los músculos involucrados. Se trasplantaron tres pares de blastemas $\mathrm{EGFP}^{+}$en la etapa de yema media en tocones recién amputados de axolotls $\mathrm{RFP}^{+}$en la misma posición del muslo para generar miembros posteriores regenerativos quiméricos de fluorescencia doble. Estos miembros regenerativos se cosecharon muy tarde mucho más allá de haber alcanzado la etapa de diferenciación tardía. Las imágenes de fluorescencia de estos miembros en secciones transversales revelaron que en la parte remanente proximal de la fibra muscular, la reconexión se produjo a un ritmo diferente entre los músculos. En el músculo grácil, la reconexión comenzó desde la periferia antes de completarse. Además, las fibras musculares $\mathrm{RFP}^{+}$contribuyeron a la regeneración muscular en las partes regenerativas distales. Curiosamente, esta contribución de glóbulos rojos se limitó a los músculos superficiales ventrales de la pantorrilla. Este tipo de modelo de regeneración quimérica de doble fluorescencia del miembro puede ayudar a aumentar la comprensión del patrón de la regeneración del miembro del Axolotl en etapas tardías.

PALABRAS CLAVE: Transgénico; EGFP; RFP; Trasplante de blastema; Fusión muscular.

\section{REFERENCES}

Ashley-Ross, M. A. The comparative myology of the thigh and crus in the salamanders Ambystoma tigrinum and Dicamptodon tenebrosus. J. Morphol., 211(2):147-63, 1992

Butler, E. G. Regeneration of the urodele forelimb after reversal of its proximo-distal axis. J. Morphol., 96(2):265-81, 1955.

Casco-Robles, M. M.; Yamada, S.; Miura, T.; Nakamura, K.; Haynes, T.; Maki, N.; Del Rio-Tsonis, K.; Tsonis, P. A. \& Chiba, C. Expressing exogenous genes in newts by transgenesis. Nat. Protoc., 6(5):600-8, 2011.

Dinsmore, C. E. Urodele limb and tail regeneration in early biological thought: an essay on scientific controversy and social change. Int. J. Dev. Biol., 40(4):621-7, 1996.

Diogo, R.; Murawala, P. \& Tanaka, E. M. Is salamander hindlimb regeneration similar to that of the forelimb? Anatomical and morphogenetic analysis of hindlimb muscle regeneration in GFPtransgenic axolotls as a basis for regenerative and developmental studies. J. Anat., 224(4):459-68, 2014. 
Diogo, R.; Ziermann, J. M.; Molnar, J.; Siomava, N. \& Abdala, V. Muscles of Chordates: Development, Homologies, and Evolution. Pectoral and Pelvic Appendicular Muscle Evolution from Sarcopterygian Fishes to Tetrapods. Florida, Chemical Rubber Company Press, 2018.

Fei, J. F.; Schuez, M.; Knapp, D.; Taniguchi, Y.; Drechsel, D. N. \& Tanaka, E. M. Efficient gene knockin in axolotl and its use to test the role of satellite cells in limb regeneration. Proc. Natl. Acad. Sci. U. S. A., 114(47):12501-6, 2017

Huang, T. Y.; Chang, C. C.; Cheng, N. C.; Wang, M. H.; Chiou, L. L.; Lee, K. L. \& Lee, H. S. Re-epithelialization of large wound in paedomorphic and metamorphic axolotls. J. Morphol., 278(2):228-35, 2017.

Khattak, S.; Murawala, P.; Andreas, H.; Kappert, V.; Schuez, M.; SandovalGuzmán, T.; Crawford, K. \& Tanaka, E. M. Optimized axolotl (Ambystoma mexicanum) husbandry, breeding, metamorphosis, transgenesis and tamoxifen-mediated recombination. Nat. Protoc., 9(3):529-40, 2014.

Mansour, N.; Lahnsteiner, F. \& Patzner, R. A. Collection of gametes from live axolotl, Ambystoma mexicanum, and standardization of in vitro fertilization. Theriogenology, 75(2):354-61, 2011.

Nacu, E.; Glausch, M.; Le, H. Q.; Damanik, F. F. R.; Schuez, M.; Knapp, D.; Khattak, S.; Richter, T. \& Tanaka, E. M. Connective tissue cells, but not muscle cells, are involved in establishing the proximo-distal outcome of limb regeneration in the axolotl. Development, 140(3):5138, 2013.

Niwa, H.; Yamamura, K. I. \& Miyazaki, J. I. Efficient selection for highexpression transfectants with a novel eukaryotic vector. Gene, 108(2):193-9, 1991.

Okabe, M.; Ikawa, M.; Kominami, K.; Nakanishi, T. \& Nishimune, Y. 'Green mice' as a source of ubiquitous green cells. FEBS Lett., 407(3):313-9, 1997.

Sandoval-Guzmán, T.; Wang, H.; Khattak, S.; Schuez, M.; Roensch, K.; Nacu, E.; Tazaki, A.; Joven, A.; Tanaka, E. M. \& Simon, A. Fundamental differences in dedifferentiation and stem cell recruitment during skeletal muscle regeneration in two salamander species. Cell Stem Cell, 14(2):174-87, 2014.

Tanaka, E. M. Regeneration: if they can do it, why can't we? Cell, 113(5):559-62, 2003

Wu, C. H.; Chen, Y. J.; Wang, M. H.; Chiou, L. L.; Tseng, W. Y. I. \& Lee, H. S. Diffusion tensor tractography reveals muscle reconnection during axolotl limb regeneration. PLoS One, 12(3):e0173425, 2017.

Wu, C. H.; Huang, T. Y.; Chen, B. S.; Chiou, L. L. \& Lee, H. S. Longduration muscle dedifferentiation during limb regeneration in axolotls. PLoS One, 10(2):e0116068, 2015.

\section{Corresponding author: \\ Hsuan-Shu Lee Institute of Biotechnology National Taiwan University 4F, No. 81 Chang-Xing St. Taipei TAIWAN}

\section{E-mail address: benlee@ntu.edu.tw}

Received: 01-04-2020

Accepted: 01-05-2020 